\title{
Glauber, Lúcia e o Cinema Novo
}

\author{
Por Dirce Waltrick do \\ Amarante
}

Joel Pizzini (1960) é cineasta e documentarista, entre seus filmes destacam-se o premiado longa-metragem 500 Almas (2004), que conta a história dos índios guatós, elogiado pela crítica nacional e internacional, e Abry (2003), quase uma autobiografia de Lúcia Rocha, mãe do cineasta Glauber Rocha, além dos poéticos Caramujo-Flor (1988) e Enigma de um Dia (1996), que representou o Brasil no Festival de Veneza..

Atualmente, Pizzini é co-diretor, junto com Paloma Rocha, filha de Glauber Rocha, do projeto de restauração dos filmes do cineasta baiano. Colabora, assim, diretamente na Fundação Tempo Glauber, no Rio de Janeiro, cujo objetivo é preservar a memória de um dos maiores nomes do cinema nacional, através da restauração de suas obras já conhecidas e algumas ainda inéditas.

Sobre o seu trabalho no Tempo Glauber e as possíveis influências de Glauber na sua própria obra, Joel Pizzini fala à "Travessia":

1. Ultimamente, você, como diretor, e Paloma Rocha, filha de Glauber Rocha, como co-diretora, estão trabalbando juntos na produção de documentários e também na restauração e produção dos DVDs, contendo a obra de Glauber Rocba. Poderia explicar esse trabalbo?

Estou envolvido no projeto de restauração e difusão digital da obra de Glauber Rocha desde 2002, quando ajudei a escrever o projeto. Imagino que pelo menos nos próximos cinco anos estaremos cumprindo essa "missão" de devolver a sua filmografia recuperada para o Brasil e o mundo. Além de acompanhar meticulosamente o processo de restauração quadro a quadro de cada filme, recorremos a todo cuidado e a uma estratégia especial para recriar o contexto em 
que cada produção foi concebida. Daí a idéia adotada de se lançar sempre dvds duplos. O primeiro com o filme propriamente dito e o segundo com um documentário de duas a três horas de duração, revelando a gênese da obra de Glauber, as etapas de produção, distribuição, a luta com a censura, bem como a repercussão do filme nos festivais internacionais.

Sinto-me honrado pelo convite feito pela Paloma Rocha para dividir essa responsabilidade e participar desse desafio que é refazer a ponte entre o cinema de Glauber (cuja obra foi interditada pela censura e teve seus negativos quando não destruídos, dispersos no exílio) e a nova geração, que tem se identificado intensamente com o ideário e a inquietação do artista. Cada filme leva em média um ano para ser restaurado, devido, sobretudo, ao estado de conservação das matrizes. Os chamados extras, que a Paloma batizou de disco da memória, implica uma pesquisa sistemática nos acervos da Cinemateca Brasileira e, basicamente, Tempo Glauber, que subsidia todos os roteiros dos documentários.

Mais do que se ater apenas ao conteúdo da obra armazenada, os documentários se permitem experiências de linguagem no âmbito documental que raramente se vêem nesta mídia, que, em geral, recorre aos chamados "extras" como forma de "rechear" de atrações os dvds. Procuramos realizar uma pesquisa de linguagem que explore as potencialidades do dvd enquanto meio de comunicação que incita o usuário à construção de uma narrativa. $O$ dvd é uma mídia em formação que sugere uma leitura fragmentada e o Depois do Transe (título do documentário que acompanha Terra em Transe) se presta a uma percepção por partes, blocos, que podem ser vistos separadamente ou por inteiro, ficando a critério do espectador.

No caso de Terra em Transe (já lançado), Dragão da Maldade e Idade da Terra, os dvds, além de duplos, contêm documentários com 13 blocos, cada um narrando a história dos respectivos filmes, sempre com um bloco dedicado ao processo da restauração de cada título.

Convém ressaltar que há de nossa parte um esforço criativo para desenvolver uma linguagem que seja adequada às características do formato dvd. Não se trata de documentários para cinema, tampouco para a televisão. Nesse sentido, elegemos como procedimento-chave a figura de Glauber em primeira pessoa, optando por uma montagem livre que articula de tal forma o seu discurso que é como se ele comentasse o seu próprio trabalho. Para fazer isso, tivemos acesso a uma longa entrevista feita pela cineasta-historiadora Raquel Gerber, em Roma, em 1973, durante o exílio do cineasta. Esse material estava gravado em fitas K-7 e foi todo restaurado para ser incorporado à estrutura narrativa dos extras.

O fascinante nessa experiência é que a obra de Glauber não admite uma abordagem acadêmica ou jornalística. Assim, a cada filme surge um novo conceito para a concepção dos documentários, os quais contam com a montagem de Ricardo Miranda, um artista que trabalhou em A Idade da Terra, e de Alexandre Gwaez, que assina Milagres, sob a sua supervisão.

A prospecção dos materiais utilizados na montagem dos documentários é outro movimento fundamental na recriação da dicção glauberiana. Em Depois do Transe, partimos das várias horas de sobras de negativos e copiões, que existiam de Terra em Transe, e que eu já havia telecinado (passado para vídeo) a fim de incorporar na montagem de Glauces, Estudo de Um Rosto [um trabalho sobre a atriz Glauce Rocha]. No 


\section{ITha de Santa Catarina}

caso de Idade da Terra, foram encontradas nas pesquisas mais de 100 latas de sobras, onde, em várias cenas, Glauber aparece dirigindo seus atores. Localizamos ainda um filme chamado No Tempo de Glauber Rocba, feito por Roque Araújo, que foi eletricista e assistente de fotografia do filme e que articulou um documentário com as sobras que foram dadas por Glauber a ele, no final das filmagens de A Idade da Terra.

2. A respeito dos roteiros inéditos de Glauber Rocha, sabe-se que eles estão concluidos e têm até story-boards, feitos pelo próprio Glauber. Ao todo, quantos roteiros inéditos o cineasta deixou? O que se pretende fazer com esse material, transformá-los em livros, filmá-los?

O Tempo Glauber acaba de conquistar um patrocínio através de um concurso público, promovido pela Petrobrás, de apoio ao Patrimônio Histórico, por meio do qual justamente será feito todo o trabalho de catalogação do acervo reunido por Lúcia Rocha durante mais de 30 anos.

Através de um decreto presidencial, o Tempo Glauber foi transformado em Arquivo de Interesse Público e Privado e, portanto, após a realização desta recuperação dos $\mathbf{1 0 0}$ mil documentos reunidos por Dona Lúcia, o público terá finalmente acesso ao legado do cineasta.

Antes deste tratamento, os documentos originais eram manipulados pelo público sem nenhum cuidado técnico, o que colocava em sério risco a integridade dos materiais.

Enquanto isto, os pesquisadores poderão acessar o site do Tempo Glauber (www.tempoglauber.com.br ), que está passando por uma fase de reestruturação e que dará as indicações e pistas necessárias para as consultas aos documentos. Foi criado ainda um site extra chamado "Uma Janela para o Novo", onde trabalharei como um dos curadores e que terá a função de destacar e selecionar documentos (textos, críticas, estudos, teses) que revelem novas interpretaçóes do pensamento de Glauber e do Cinema Novo.

\section{Eles mantêm a estética e a temática dos filmes anteriores de Glauber?}

R.: Parafraseando Fellini, Glauber fez um filme só a vida inteira, ou seja, todas as peças têm a marca inconfundível do autor, e se elas forem vistas como um todo, certamente se terá uma melhor compreensão da construção estilística de sua obra. A intenção de tornar disponível a sua produção intelectual é justamente proporcionar uma visão do conjunto da criação. A história mítica do país está lá, desvelada a cada filme, livro, poema, desenho, carta.

A meu ver, Glauber é um dos artistas (mais ' que cineasta) que mais levou ao extremo a ambição que persegue todo criador, a. e e de ser político e poético ao mesmo tempo. Essa inquietação está presente em todos os fotogramas que compõem a sequiência de sua trajetória.

4. Qual foi o papel de Lúcia Rocba, mãe de Glauber Rocba, no documentário que você dirigiu sobre o cineasta, em 2003? Ela detinba um material considerável sobre Glauber, material que boje faz parte do arquivo do Tempo Glauber. Que Glauber vem à tona nesse 
Na verdade, o Abry, de 2003, não é um filme sobre o Glauber, como a princípio poderia vir a ser, caso nos rendêssemos à tentação de "aproveitar" a oportunidade para extrair da mãe novas revelações. É claro que a imagem de Glauber está presente, mas como coadjuvante. É um filme sobre, e um filme da Lúcia Rocha, como está no subtítulo, já que mergulha no seu universo fabulador para falar de suas angústias, medos e de sua luta pela manutenção da memória, luta na qual ela emprega corpo e alma, a fim de recuperar a obra do filho. Realizado numa situação-limite, dentro de um quarto de hospital, às vezes penso que a câmera serviu como balão de oxigênio para irrigar o imaginário dessa mulher que encarna a própria história do Cinema Novo.

Hoje me dou conta que foi Dona Lúcia, por meio de Abry, que me introduziu na Era Digital. Dada a dificuldade de filmar no Hospital, sem autorização e com uma câmera portátil, eu mesmo tive de aprender a "operá-la", dividindo a função de câmera e camareiro, várias vezes tive de me revezar nessas tarefas, fazendo um enquadramento e ajudando Lúcia a se acomodar em sua cama.

O filme sedimentou nossa amizade e abriu novas pontes para as possibilidades audiovisuais.

Nunca imaginei em fazer um filme nestas circunstâncias. Mas fui levado a fazê-lo, e Lúcia sem dúvida me encorajou a enfrentar situações mais emergenciais e pungentes com esta.

E o curioso é que, enquanto Abry custou pouco mais de mil reais (o preço das fitas), o longa-metragem 500 Almas consumiu quase 1 milhão de reais. Tenho porém para com os dois filhos-filmes a mesma consideração... Cada filme pediu um tratamento diferenciado.

Em Abry, a própria precariedade do material incorporado à montagem é coerente com o estado entre a vida e a morte a que a personagem estava submetida. O filme acompanha o fluxo da consciência de uma mulher que doou sua vida para os filhos (não esquecermos que Anecy Rocha, atriz e irmã de Glauber, é evocada em $A b r y$ ), e para os filmes, e que atravessou o tempo da "ponte de safena" para fazer história. Eis a sinopse do filme:

"Aos 84 anos de idade Lúcia Rocha, criadora do Tempo Glauber, interna-se num hospital em São Paulo para fazer exames no coração. Ao receber a notícia sobre o risco que corria sua vida, Lúcia, lacônica, diz ao médico - Então abre! É a segunda vez que ela submete-se a uma cirurgia de pontes de safena. A partir deste gesto, nasce o documentário Abry (com $\mathrm{y}$, signo do inconsciente, de acordo com a nomenclatura inventada pelo filho Glauber Rocha). Para relatar suas memórias, ela convida o cineasta Joel Pizzini, que oferece sua mini-câmera como instrumento amplificador do imaginário de Lúcia. "Abry" é um mergulho poético no universo fabulador de Lúcia Rocha, reconstruindo sua trajetória no cinema brasileiro através de sons, imagens e personagens com quem conviveu de perto." 
5. A sua parceria com Paloma Rocba é posterior ao documentário Abry ou ela já teve algum papel na construção do documentário?

Minha parceria com Paloma Rocha vem exatamente da realização de Abry, quando então a conheci dentro do Hospital em São Paulo. Co-realizamos o filme, em condições mínimas de produção e execução, e a partir daí inventamos outros rebentos, como Retrato da Terra (ensaio sobre a obra de Glauber) e Elogio da Luz (sobre a obra de Rogério Sganzerla), ambos produzidos a convite do Canal Brasil. Na sequiência, vieram os documentários-extras dos dvds, Depois do Transe, o documentário Anabazys (sobre A Idade da Terra) e Milagres (sobre o Dragão da Maldade contra o Santo Guerreiro), não lançado ainda.

A parceria se estende ao trabalho em si de restauração dos filmes de Glauber e à colaboração em projetos como Dormente e Manual de Barros, em que Paloma assina a Produção Executiva de tais filmes.

\section{Como é a sua atuação boje no Tempo Glauber? Quais seus projetos nesta instituição?}

Creio que a Paloma Rocha está mais habilitada a responder essa questão. Sou um colaborador da instituição e ela responde pela filosofia da entidade.

Trabalho como um dos curadores do site, atualmente, e como co-diretor do projeto de restauração e de difusão digital da obra de Glauber. Sou co-diretor dos documentários que compóem os extras dos dvds de cada clássico do autor.

7. De que maneira a estética de Glauber, seu "cinema de poesia", influi na estética de Joel Pizzini?

o que me interessa essencialmente em Glauber e que de certa forma influi e ilumina o meu trabalho é a sua postura intransigente em nome da fabulação de sua linguagem.

É um artista que se descolou, se descolonizou e projetou sua luz própria no mundo. Teve uma passagem meteórica pela terra, morreu aos 42 anos e deixou uma obra que é um "claro enigma", que, no meu caso, é fonte permanente de inspiração para futuros vôos e reflexões. Há uma geração de autores que rejeitam a sua figura e se sentem ameaçados pelo padrão de exigência imposto pela sua filmografia. Preferem negá-lo (como o caso do diretor de Cidade de Deus) e desejam que seu cinema permaneça armazenado nas prateleiras das cinematecas.

Daí, a meu ver, o caráter político que envolve esse projeto de restauração, que às vezes inconscientemente provoca um imenso incômodo na classe cinematográfica, com raras exceções. Para o "cinema de resultados" que se faz hoje no Brasil, a figura de Glauber é uma referência inconveniente, por provar que é possivel produzir um cinema inventivo, econômico e alternativo às formulas apelativas e gastas que dominam o imaginário audiovisual contemporâneo.

Vou até mais longe: penso que a vanguarda hoje no Brasil está na retaguarda! 
Afinal, não só a obra de Glauber, mas a obra de Joaquim Pedro de Andrade, de Leon Hirszman, de Saraceni, de Person, entre outros, é obra praticamente inédita para o grande público. É um cinema que foi interditado e quase sucumbiu num hiato que se impôs à nossa memória, no final dos anos sessenta. Partindo desse pressuposto, não podemos tratar estes filmes como produtos circunscritos ao passado nem, simultaneamente, podemos pô-los simplesmente de volta no mercado, sem um trabalho sistemático de recriação do ambiente em que foram gerados.

Para Glauber o cinema era quase uma religião, sem concessőes ao circunstancial e às barganhas de produção. Nessa direção ele é um farol. Ao mesmo tempo, se cairmos na tentação de copiá-lo, ele pode também se tornar uma sombra, um fantasma.

8. Quais são seus novos projetos? Você está trabalbando num novo filme?

Atualmente, estou trabalhando no terceiro tratamento do roteiro de Mundéu - A Invenção de Limite, sobre a aventura de Mário Peixoto na criação de seu clássico de vanguarda Limite, produzido em 1930 no Brasil. Tenho desenvolvido outros projetos, ainda, como "Viaggio in Brasile", baseado na passagem de Roberto Rossellini no Brasil no final dos anos cinqüenta e sessenta, além de organização de Mostras de Cinema. Paralelamente, continuo realizando ensaios, para o Canal Brasil (Ney Matogrosso será o próximo) e o diálogo com a dança contemporânea, que resultará em Elogio da Sombra, em fase de montagem.

Preparo-me no momento para o lançamento, no circuito de cinema, do longa-metragem 500 Almas. 